\title{
Industrial System Energy Efficiency Assessment Using System Dynamics
}

\author{
Ming Zeng ${ }^{1, ~ a ~}$, Guojun Wang ${ }^{1, b}$, Haojing Wang ${ }^{1, c}$, Yuming Gao ${ }^{2, d}$, \\ Liang Guo ${ }^{2, \text { e }}$, Jian Zhang ${ }^{2, \mathrm{f}}$, Huadong Zhang ${ }^{2, g}$ \\ ${ }^{1}$ School of North China Electric Power University, Beijing 102206, China \\ ${ }^{2}$ State Grid Shan Dong Electric Power Company, Shandong 250001, China \\ azengmingbj@vip.sina.com, bwugengmath@163.com, cwanghaojing2010@163.com, ${ }^{d} 532278426$ \\ @qq.com, ${ }^{\mathrm{e}} 2398095960 @ q q . c o m,{ }^{\mathrm{f}} 284528290 @ q q . c o m, 9984371984 @ q q . c o m$
}

Keywords: Energy consumption, system dynamics, industry.

\begin{abstract}
China, the world's biggest energy consumer, is now facing a severe challenge in energy supplies. While industrial production contribute most of the energy consumption and pollution in China, it is necessary to optimize its energy management. This paper will focus on energy consumption management of industrial enterprise and build a simulation model using system dynamics. A case study will be introduced and conclusion will be given.
\end{abstract}

\section{Introduction}

\subsection{Background.}

China, the world's biggest energy consumer, is now facing a severe challenge in energy supplies. At the same time the world strengthening energy conservation and taking the road to a low carbon economy, the new large-scale energy revolution is under the way. While segments of Chinese industry are considered energy intensive but have significant potential for improved efficiency as some energy extensive enterprise has inefficient equipment and poor energy management.

While industrial production contribute most of the energy consumption and pollution in China, it is necessary to optimize its energy management and reduce the wastage of energy. Meanwhile by reducing the cost of energy, enterprises can also achieve greater profits.

\subsection{Study area.}

This paper focus on energy utilization efficiency of industrial enterprise. To improve energy efficiency, we need to study an enterprise's energy utilization system (EUS) and try to imitate its behavior.

There are some research on this field. In [1], energy utilization efficiency were evaluated by generating a benchmarking model. But it requires for business information and data from competitors to run this model which is difficult to obtain in today's commercial space. Energy analysis model document two pairs of energy efficiency factors were analyzed, was established. In some studies energy utilization process were careful analyzed, and efficiency assessment model was established [2, 3]. However, these models are static and could not show the interaction of factors. Thus, a system dynamic model is introduced in this paper to simulate the EUS behavior and try to optimize it.

\section{EUS Model}

\subsection{Model Design.}

In EUS, the system of energy utilization has been break down into process to analyze the interaction of each producing actions and factors. Three main factors which cause the ineffective energy consumption are: ineffective of staffs, ineffective of tools and ineffective of machines.

We consume that the ineffective energy consumption of staffs only include strikes and the idling time which result in ineffective of energy consumption. The ineffective of tools are caused by tool breakdown \& regeneration and the waste in finding tools. Then the ineffective consumption of 
machines are affected from 7 factors: procedure connection waste, improper production plan, upstream \& downstream outage, machine starting waste, failure of machine, regular maintenance and rejected/rework products[4].

There are two management factors which can act on the factors over and improve energy utilization efficiency--lean management invest and employee motivation.

The total effective and ineffective energy consumption contribute to daily energy consumption cost and has effect on the profit.

\subsection{Model Structure.}

We use the Vensim - the system dynamic analysis tool to build the EUS structure. Fig.1 depicts stock-flow diagram of the model.

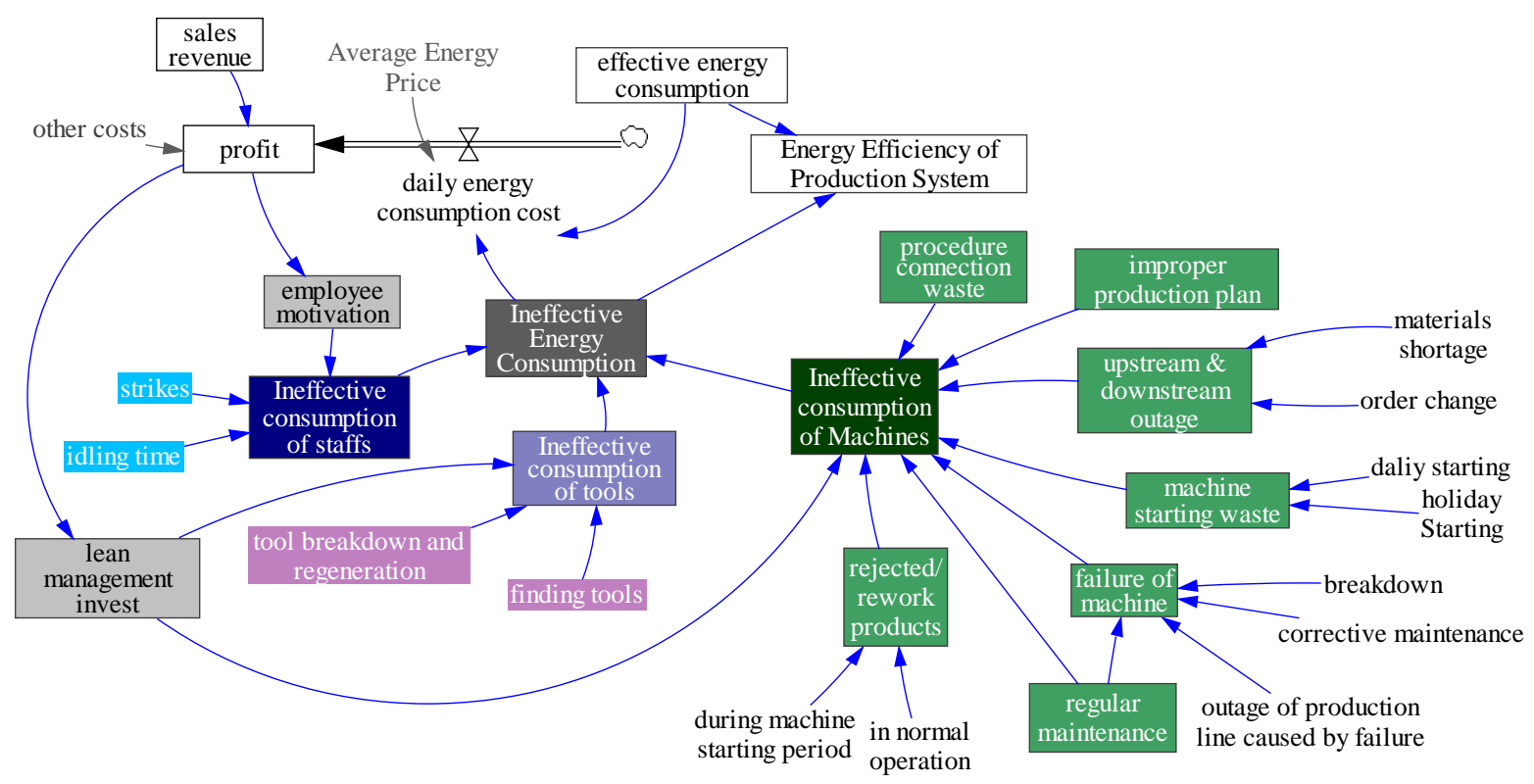

Fig. 1 A stock-flow diagram for EUS

\subsection{Model Algorithm.}

There are two sectors of this model: ineffective energy consumption sector and cost \& profit sector.

(1) Ineffective energy consumption

Ineffective Energy Consumption= Ineffective consumption of staffs + Ineffective consumption of tools+ Ineffective consumption of Machines.

Ineffective consumption of staffs= strikes+ idling time- f1(employee motivation).

Ineffective consumption of tools= tool breakdown and regeneration+ finding tools- $\mathrm{f} 2$ (lean management invest).

Ineffective consumption of Machines= procedure connection waste+ improper production plan + upstream \& downstream outage+ machine starting waste+ failure of machine+ regular maintenance + rejected/rework products- f3(lean management invest).

The energy consumption need to be turned into electricity and united by kilowatt-hour. $\mathrm{f} 1$ is the equation how employee motivation(\$) act on Ineffective consumption of staffs which is invited from [5]. And f2 and f3 show how lean management invest (\$) affect Ineffective consumption of tools and machines which are invited from [6].

(2) Cost and profit

Daily energy consumption cost $=$ (effective energy consumption + Ineffective Energy Consumption)* Average Energy Price.

Profit $=$ sales revenue- daily energy consumption cost- other costs.

Energy Efficiency of Production System= effective energy consumption/ (effective energy consumption+ daily energy consumption cost)

Employee motivation $=$ profit ${ }^{*} \alpha$

Lean management invest $=$ profit $* \beta$ 
In function (5), the average energy price $(\$ / \mathrm{kWh})$ are average electricity price in observation period. In function (8) $\alpha$ is the certain percentage employee motivation (\$) fee set from profit (\$), and $\beta$ in function (9) is the lean management invest (\$) set from profit.

\section{Case Study}

A Electronics Manufacturer is chosen to illustrate the application of EUS model. We take 1week as a term and all the consumption in the model are observed and recorded while the cost and revenue can also obtained from financial data. The main energy used in this enterprise is electricity and other sources can be ignored.

Vensim is used to run the model while two senses_-base and scenarios-are simulated.

\subsection{Base Run.}

The base run is consumed to be the actual situation of the enterprise when none of the management measure has been taken. In the model, employee motivation and lean management invest value 0 . Time bounds are set as follow:
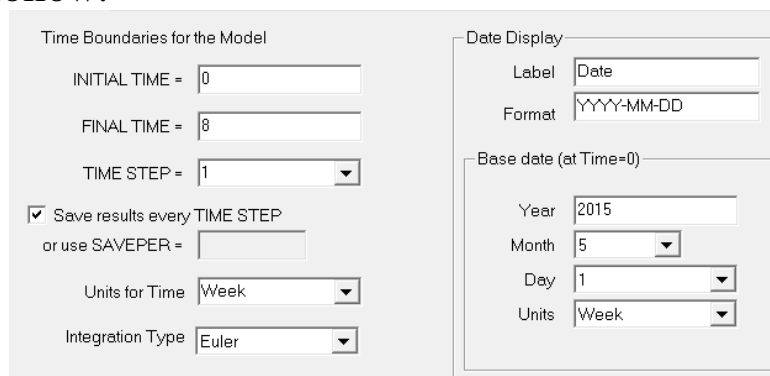

Fig. 2 Time bounds settings

\subsection{Scenario simulation.}

In scenario simulation, all the parameters are set as same as base run except the two management indexes: employee motivation and lean management invest. They are used to enhance the energy management of enterprise. The parameter $\alpha$ is set as 0.02 in equation (8) and $\beta$ as 0.05 in equation (9). These management fee are share equally into every day cost in a year and the detail management means is refer to [5] and [6].

\subsection{Results.}

The main detective parameters in this model are Energy Efficiency of Production System. The results of two simulations are compared as the following graph.

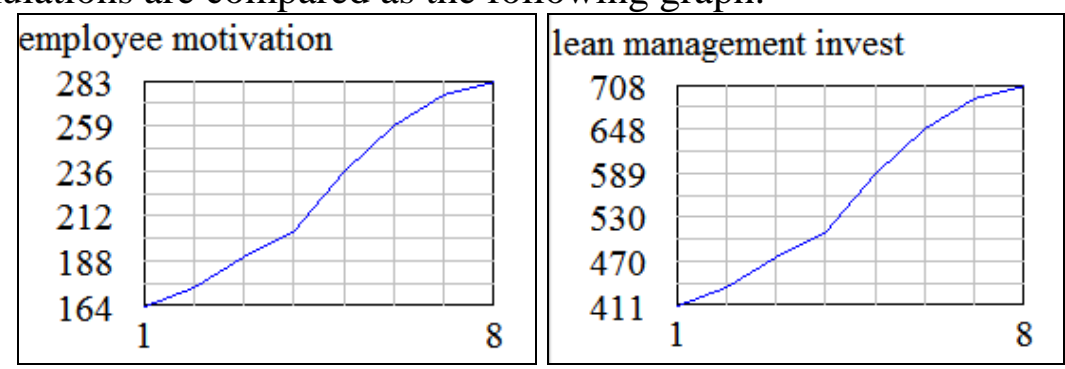

Fig. 3 Two parameters in scenario simulations

The performance of employee motivation and lean management invest parameters are shown in graph above. They share a same profile but a different value because they are from different times of profit. The increase of two parameters are from steep to slow reflect the increase of profile.

It can be seen from the graph that after take management measures, the efficiency of production systems are increased by about 0.083 percentage. The vertical distance of two lines is the increase of the efficiency. The distance is narrow at first and grow wide with times which owes to the effective management. That the distance first increase fast and then becomes slower is because the sensitive of effect of management is getting weaker to the management invest. 


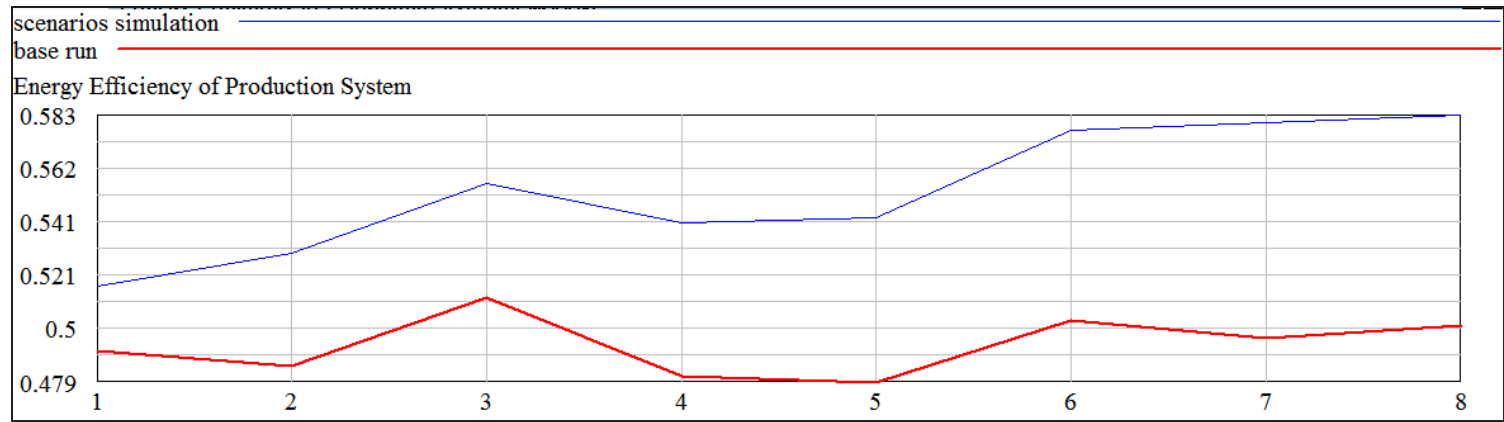

Fig. 3 Energy Efficiency of Production System in two simulations

\section{Summary}

This paper provide a method to analyze and simulation the energy utilization system by establishing a EUS and modeling with system dynamic method. The case study is invited and the result shows the validity of this model. It can be concluded that the efficiency of energy consumption can be improved to a certain degree by effective energy utilization management.

\section{Acknowledgements}

Science and Technology Project of State Grid Corporation of China (Research and Application of Key Technologies in Smart Grid Park Energy Management and Optimization for Smart City)

\section{References}

[1]. Shan Shaolei, Wang Ning, Zhang Xinping, et al. A Probe into Establishing Enterprises Energy Efficiency Benchmarking Model. China Resources Comprehensive Utilization. Vol. 27 (2009) No. 4, p. 4-6.

[2]. Christian Mose, Nils Weinert. Process chain evaluation for an overall optimization of energy efficiency in manufacturing-the welding case. Robotics and Computer-Integrated Manufacturing. Vol. 34 (2015), p. 44-51.

[3]. Trang Thuy Nhu, Thomas Schaubroeck, Steven De Meester, et al. Resource consumption assessment of Pangasius fillet products from Vietnamese aquaculture to European retailers. Journal of Cleaner Production. Vol. 100 (2015), p. 170-178.

[4]. Gökan May, Ilaria Barletta, Bojan Stahl, et al. Energy management in production: A novel method to develop key performance indicators for improving energy efficiency. Applied Energy. Vol. 149 (2015), p. 46-61.

[5]. V. I. Borzenko, T. V. Pyatak. Impact of Finance and Moral Labor Incentives of the Enterprise's Personnel of the Efficiency of Their Work. JOURNAL OF JIANGSU TEACHERS UNIVERSITY OF TECHNOLOGY. Vol. 17 (2011), No. 6, p. 52-56.

[6]. Dong Peng, Xiong Huanyan, Wei Dong. Production process optimization research based on the value stream map. Modern Accounting. Vol. 11(2014), p. 25-30. 